Biochem. Lett., Vol. 5, PP. 113-118 (2009)

\title{
EFFECT OF GLUCOCORTICOIDS ON PIT 1 INHIBITION OF SV40 ENHANCER ACTIVITY
}

\author{
S. El-Jaafary, A. B. EL Fighi and S. A .B. Hasan \\ Department of Biochemistry Faculty of Medicine \\ AL-Fateh University Tripoli, S.P.L.A.J
}

\begin{abstract}
ABSRACT
Earlier studies had shown an effect of glucocorticoids receptor on Pit 1 activation of rPrl promoter activity Treacy. Therefore, the effect of glucocorticoids on Pit 1 inhibition of SV40 enhancer function was investigated in a series of co-transfection studies into glucocorticoids receptor deficient $\mathrm{CV}-1$ cells. Under identical conditions co-transfection of $C M V$ - Pit 1 activated transcription from prPrl (-1960-+38) - CAT; however, expression of GR in the presence of dexamethasone (10-6M) suppressed this activation. The effect of glucocorticoids on the inhibition of SV40 enhancer activity by Pit 1 was investigated. In co- transfection studies in CV-1 cells (Figure 4) it was shown that GR expression and the provision of glucocorticoids (dexamethasone 10-6M) blocked the ability of Pit 1 to inhibit SV40 enhancer activity. Under the same conditions the ability of Pit 1 to activate the rPrl promoter $(-1960 /+38)$ was inhibited.
\end{abstract}

\section{INTRODUCTION}

Earlier studies had shown an effect of glucocorticoids receptor on Pit 1 activation of $\mathrm{rPrl}$ promoter activity Treacy et al. ${ }^{(\mathbf{1})}$. Therefore, the effect of glucocorticoids on Pit 1 inhibition of SV40 enhancer function was investigated in a series of co-transfection studies into glucocorticoids receptor deficient $\mathrm{CV}-1$ cells (Figure 1), cotransfection of CMV - Pit 1 with pSV2 -CAT suppressed the level of 
receptor gene expression markedly below control (lanes 1 \& 2), additional transfection of pRSV $-\mathrm{GR}$ in the presence of dexamethasone reversed the effect of Pit 1 (lane 3). Under identical conditions co-transfection of CMV - Pit 1 activated transcription from $\operatorname{prPrl}(-1960-+38)-\mathrm{CAT}$; however, expression of GR in the presence of dexamethasone (10-6M) suppressed this activation.

\section{MATERIALS \& METHODS}

An SV-40 enhancer fragment was isolated by restricting pSV2-CAT with Sph 1. It was gel purified and ligated into pRSV (enhancer minus) - CAT (Sph1 restricted), transformed into E.coli (strain HB $101)$, followed by mini - preparation and selection of the plasmid, $\mathrm{pR}$ (-)-SV40E-CAT (Figure 2). It was large scale prepared and purified by tow successive bandings through $\mathrm{CsCl}$ - ethidium bromide gradients. Sambrook, J. (1989) the structure of pR (-) SV40-CAT and its restriction analysis with a range of different restriction enzymes (Figure 3).

\section{RESULTS}

It was of interest to investigate the activity of the SV40 early gene enhacer/promoter system in various cells types. Studies on the SV40 enhacer/promoter have shown it to be active in a wide range of cells eg. C6, C127, CV-1 and Hela cells Treacy et al. ${ }^{(4)}$. the effect of glucocorticoids on the inhibition of SV40 enhancer activity by Pit 1 was investigated. Both Camper et al. (2) and Adler et al. (1) have shown that glucocorticoids suppress prolactin promoter activity Adler et al. (1) showed that the over expression of the glucocorticoids receptor repressed prolactin promoter function. In co- transfection studies in CV-1 cells (Figure 4) it was shown that GR expression and the provision of glucocorticoids (dexamethasone 10-6M) blocked the ability of Pit 1 to inhibit SV40 enhancer activity. Under the same conditions the ability of Pit 1 to activate the $\mathrm{rPrl}$ promoter $(-1960 /+38)$ was inhibited. 


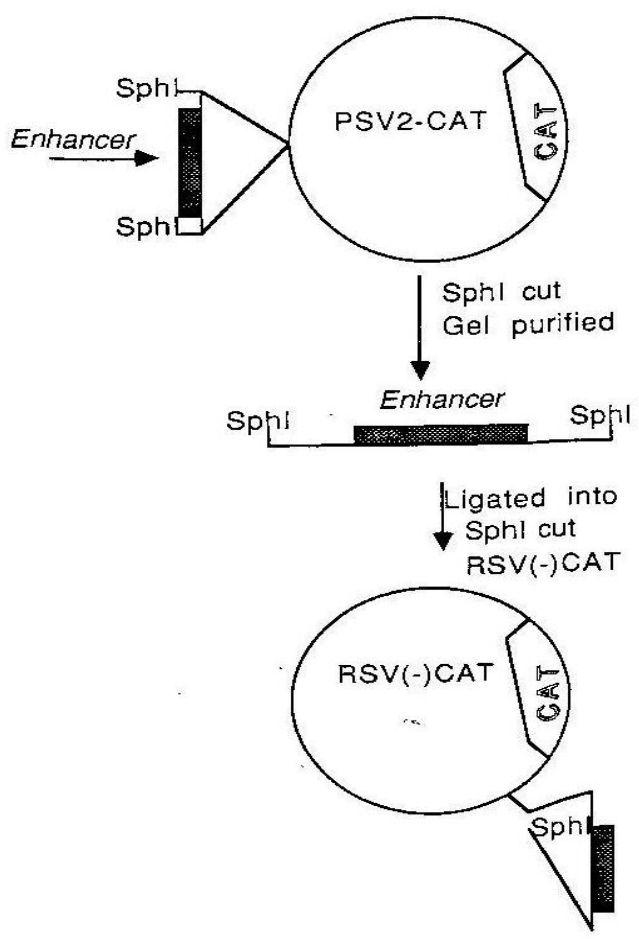

Fig Subcloning strategy used to insert a unit of the 72 bp SV4O enhance into pRSV(enhancer-minus) ${ }_{S p h l}$ CAT construct. 


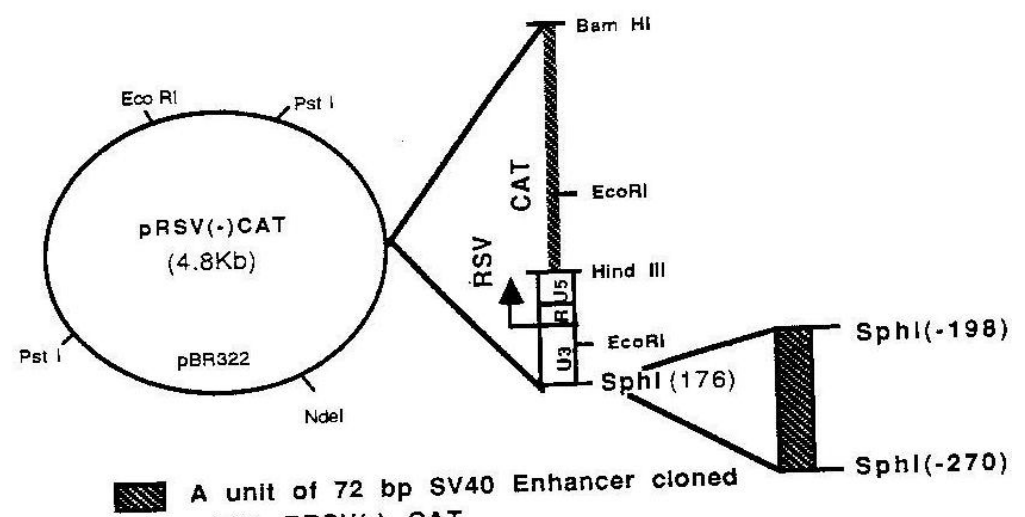
into PRSV $(\cdot)$ CAT

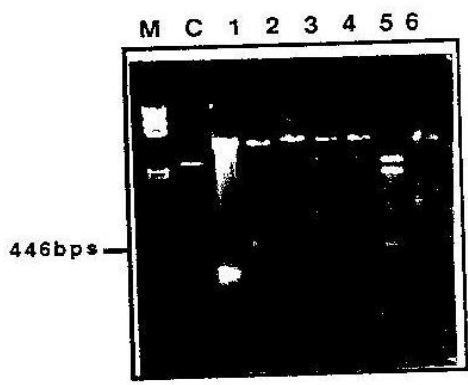

Flg Plasmid map and restriction analysis of pRSV(ennncer-minus)/SV40enhancer)CAT.

Analysis shows:Lane1: pRSV(enhancer-minus)CAT, cut Sphl(4,803bps) Iane 2:pRSV(SV40-E)CAT, cut Hindlil/Ndel, $(4,429 ; 446 \mathrm{bps})$, lane3: HinndII cut $(4,875)$, lane 4:BamHI cut(4,875bps), lane5:EcoRI cut(2,331; 2,100;339bps), lane6: Pstl cut(3,917,958bs), lanec:unrestricted plasmid. Micorresponds to Hindill cut phage $\lambda$ DNA. 


\section{Effect of glucocorticoid}

\section{CV-1}

A.

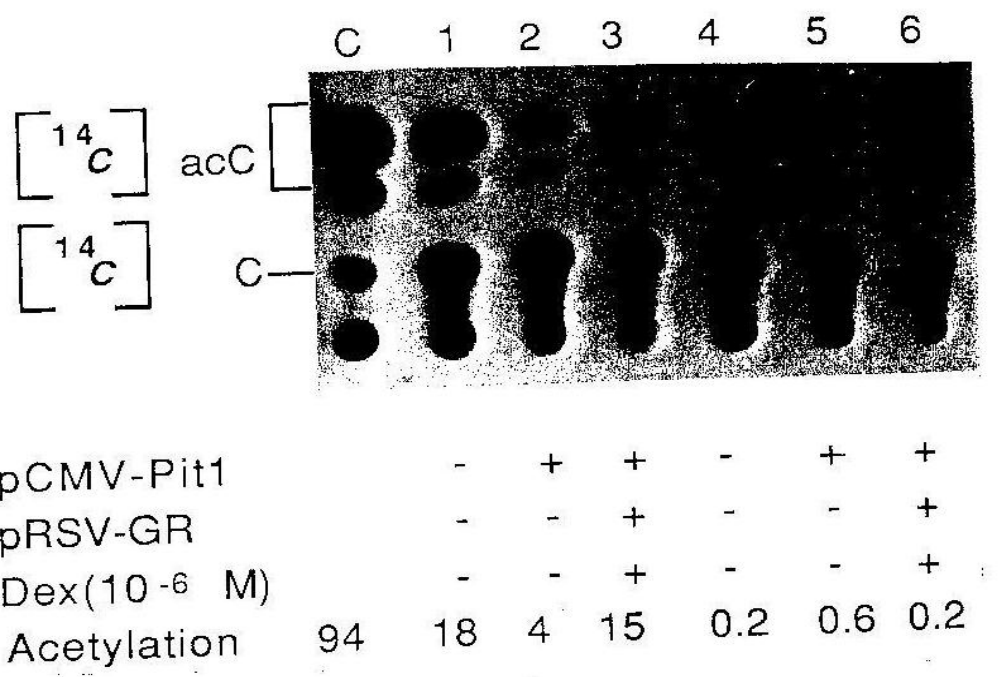

$\%$ Acetylation

B.
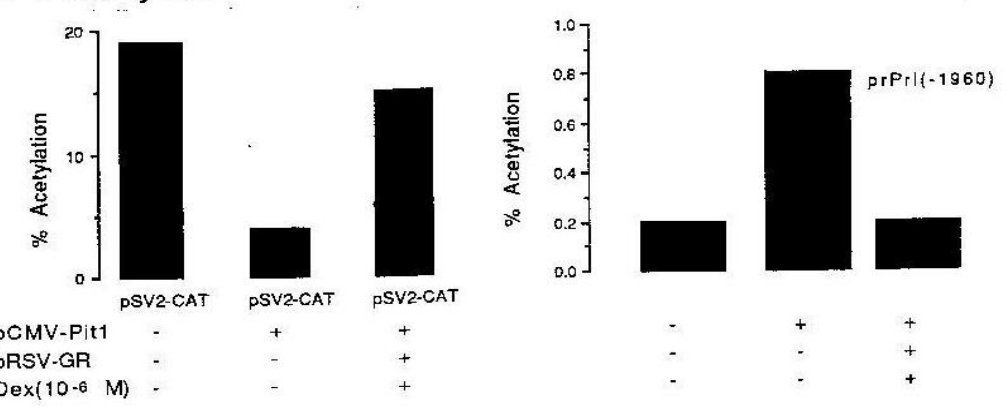

Fig : Effect of glucocorticoids on the SV40-enhancer after co-transfection with pCMV-Pity into non pituitary cells.

(A) Shown is an autoradiograph of a representative CAT enzyme assay indicating the effect of pCMV-Pit1 activity on co-transfection into CV-1 cells with pRSV-GR in the presence and absence of dexamethasone $(10-6 \mathrm{M})$ : Lanes1-3: pSV2-CAT lanes 4-6: prPrl(-1960/+38)-CAT, laneC: represents where pure CAT enzyme was incubated in place of cell extract. Values for CAT activity are presented as $\%$ acet ylation of $[14 \mathrm{C}]$-chloramphenicol.

(B) Shown is the mean CAT activity from 3 independent experiments presented as \% acetylation of [14 C]-chloramphenicol observed in $\mathrm{CV}-1$ cells co-transfected with pSV2-CAT and PCMV-Pit1 in the presence and absence of dexamethasone $\left(10^{-6} \mathrm{M}\right)$. The effect on prPrl(-1969/+38)-CAT is shown for comparison.

*lucocorticoid-Receptor expression vector. 


\section{DISCUSSION}

It was of interest to investigate the activity of the SV40 early gene enhacer/promoter system in various cells types. Studies on the SV40 enhacer/promoter have shown it to be active in a wide range of cells eg. C6, C127, CV-1 and Hela cells Treacy et al. (4). The effect of glucocorticoids on the inhibition of SV40 enhancer activity by Pit 1 was investigated. Both Camper et al. (2) and Adler et al. (1) have shown that glucocorticoids suppress prolactin promoter activity Adler et al. (1) showed that the over expression of the glucocorticoids receptor repressed prolactin promoter function. In co- transfection studies in CV-1 cells (Figure 4) it was shown that GR expression and the provision of glucocorticoids (dexamethasone 10-6M) blocked the ability of Pit 1 to inhibit SV40 enhancer activity. Under the same conditions the ability of Pit 1 to activate the rPrl promoter $(-1960 /+38)$ was inhibited.

\section{REFERENCES}

1- Adler, S., Watremann, M.l., He, L. and Rosenfeld, M.G. (1988): Steroid receptor mediated inhibition of rat prolactin gene expression does not require the receptor DNA- binding domain. Cell, 52,685-695

2- Camper, S.A., Yao, Y.S.A. Rottman, F.M. (1985): Hormonal regulation of the bovine prolactin promoter in rat pituitary tumour cells. J. Biol. Chem. 260, 12246-12251.

3- Sambrook, J., Maniatis, T., Fritch, E.F. (1989): Molecular cloning a laboratory manual volume 3. Cold spring Harbor, New York

4- Treacy, M.N, Ryan, F. and Martin, F. (1990): Functional glucocorticoids inducible enhancer activity in the 5-flanking sequences of the rat growth hormone gene, J. Steroid Biochem. And Mol. Boil 